\title{
Integración regional en tiempos de pandemia de COVID-19
}

POR SANDRA C. NEGRO $(*)$

\begin{abstract}
Sumario: I. Escenarios pre-COVID-2019.- II. Marco teórico de la integración regional.- III. La integración subnacional: inclusión y exclusión.- IV. La dimensión internacional de la integración regional.- V. Las reacciones de la integración regional ante la pandemia de COVID-19.- VI. Reflexiones finales.- VII. Bibliografía.
\end{abstract}

Resumen: la pandemia de COVID-19, que en el año 2020 sorprendió a los estados y a las organizaciones internacionales, impactó en el escenario de la integración regional, obligando a respuestas de contingencia, inicialmente pensadas para enfrentar la crisis sanitaria. El devenir de los acontecimientos y las sucesivas "olas" que continúan azotando a la humanidad hicieron necesarias estrategias más profundas y activas, hasta el punto de exigir el diseño e implementación de una verdadera política. Este trabajo busca explorar los caminos transitados por la integración regional en el escenario pre COVID, relatar las acciones implementadas por la UE y el Mercosur frente a la actual pandemia y avizorar horizontes de reactivación en un futuro próximo.

Palabras claves: integración regional - escenarios - pandemia - crisis - estrategias

\section{Intégration régionale à l'époque de la pandémie COVID-19}

Résumé: la pandémie COVID-19, qui a surpris les États et les organisations internationales en 2020, a eu un impact sur le scénario d'intégration régionale, forçant des réponses d'urgence, initialement conçues pour faire face à la crise sanitaire. Le déroulement des événements et les "vagues» successives qui continuent de frapper l'humanité, ont rendu nécessaire la conception de stratégies plus profondes et plus

(*) Dra. en Derecho, Universidad de Buenos Aires (UBA). Magister en Políticas y Gestión de la Ciencia y la Tecnología (UBA). Magister en Relaciones Internacionales, Universidad de Belgrano (UB). Magister en Gestión de Negocios y Formación Profesional para la Integración Latinoamericana, Universidad de Ciencias Empresariales y Sociales (UCES). Prof. Titular Regular de Derecho de la Integración, Facultad de Derecho, Universidad de Buenos Aires (UBA). Prof. Adjunta regular de Teoría del Estado y Derecho Internacional Público, Universidad de Buenos Aires (UBA). Investigadora principal y directora del Centro de Estudios Interdisciplinarios de Derecho Industrial y Económico, Facultad de Derecho, Universidad de Buenos Aires (UBA). 
actives au point d'exiger la conception et la mise en ouvre d'une véritable politique. Ce travail essais d'explorer les voies empruntées par l'intégration régionale dans le scénario pré-COVID, à relier les actions mises en ouvre par l'UE et le Mercosur face à la pandémie actuelle et à envisager des horizons de réactivation dans un proche avenir.

Mots-clés: intégration régionale - scénarios - pandémie-crise - stratégies

\section{Escenarios pre-COVID-2019}

Los nacionalismos, la globalización económica y la integración regional son tres escenarios distintos y muchas veces coincidentes en el tiempo y en el espacio geográfico.

En primer lugar, en el primer escenario se observan los nacionalismos con la consecuente explosión de conflictos localizados, que han caracterizado los últimos setenta años. En este contexto, son numerosas las sociedades (varias de ellas muy antiguas y aparentemente bien consolidadas) en las cuales la cuestión nacional está vigente y donde problemas tribales, frecuentemente vinculados a identidades étnicas y regionales, son fuertes, dando lugar al denominado "nacionalismo agresivo" (Berlin, 1983, p. 434). Asimismo, formas de separatismos religiosos, políticos o lingüísticos reaparecen y sus reclamos son frecuentes o constantes (ejemplos como los de Cataluña, Escocia, País Vasco, Flandes, Kosovo, Chechenia, Kurdistán, Sahara Occidental, el Tíbet, entre otros).

Así, la idea de conflicto está latente tanto en conflictos de alcance bilateral como regional. Los mismos reconocen una pluralidad de causas relacionadas con el concepto de nación: lengua, religión y raza. Basta recorrer distintos puntos geográficos como Nagorno Karabaj, Chechenia, Georgia, Ruanda y Somalia para apreciar que en algunos casos coinciden el conflicto y el deterioro o disolución de "estados artificiales".

Por su parte, los conflictos entre el gobierno central y el gobierno periférico son característicos en los casos de Cataluña o el País Vasco. Ciertamente, con sus particularidades y distinciones, también son expresiones de singularidades en función del Estado que los contiene.

En tal sentido, “(...) casi en cualquier parte a donde se volviera la vista, la gente, ha estado preguntándose ¿quiénes somos?, ¿adónde pertenecemos? y ¿quién no es de los nuestros? Estas preguntas son fundamentales, no sólo para los pueblos que están intentando forjar estados nacionales, como sucede en la antigua Yugoeslavia, sino también en un sentido mucho más general" (Huntington, 1997, p. 197). 
En segundo término, el concepto de "globalización" (Messner, 1999), que pretendió resumir en forma abarcadora la nueva realidad contemporánea, expresa parte de los cambios que se están produciendo, vinculados al paradigma que parece señalar el horizonte de los estados-naciones: el de su interdependencia recíproca a un nivel desconocido hasta el presente (Keohane, 2012).

En este contexto, una tercera aproximación, resulta de especial interés. Es la interacción de los Estados en el marco de la integración económica regional. Las experiencias en curso en América Latina (Mercosur, la Comunidad Andina de Naciones -en siglas, CAN—, la Alianza del Pacífico, Prosur, ALADI, CARICOM, SICA, SIECA) u otros en Asia - por ejemplo, ASEAN, APEC o la reciente RCEP(Carbone, 2020) o África -AfCFTA- (Fofack, 2018), así como el proceso de la Unión Europea (UE) ponen en evidencia que la integración se consolida más rápidamente cuando reposa sus cimientos en la coincidencia cultural y en la conciencia común de pertenencia. Además, la tendencia a crear bloques o agrupaciones donde el intercambio comercial preferencial establece líneas de atracción entre algunas sociedades, a la vez que posibles enfrentamientos entre bloques a través de la imposición de restricciones comerciales recíprocas, planteando así disputas comerciales en cuanto a la legalidad de las medidas adoptadas. Hacia fines del siglo XX, en 1996, Renato Ruggiero, el entonces director de la Organización Mundial del Comercio (OMC) manifestó la importancia de que las distintas formas de integración económica se insertasen en el concepto de "regionalismo abierto", es decir, se comportasen como herramientas de facilitación de la liberalización gradual y progresiva del comercio mundial haciendo compatible el regionalismo con el multilateralismo.

Pero a partir de 2020, la pandemia de COVID-19 ha hecho evidente la importancia de las fronteras de los Estados, utilizadas por los gobiernos para tratar de detener la circulación del virus, imponiendo restricciones y prohibiciones para la circulación de bienes y en especial de personas y, a la vez, la insuficiencia y la impotencia de tales intentos gubernamentales ante la propagación de la enfermedad.

El examen de la integración regional y el multilateralismo nos obligan a pensar en el escenario de pandemia y, probablemente, en los escenarios de la post pandemia que mostrarán nuevos límites a la interdependencia entre Estados dando lugar a reivindicaciones estatales para afrontar los problemas sanitarios y las crisis económicas derivados del COVID-19 y a nuevas lecturas de la soberanía estatal.

Estados soberanos y a la vez interdependientes, con la subregión o en experiencias de integración regional junto con el debilitamiento del sistema multilateral del comercio y de las organizaciones internacionales como la Organización Mundial de la Salud, están presentes y "cohabitan" generando un clima de "inestabilidad" atravesado, en algunos casos, por conflictos al interior o entre los 
Estados. Por ende, es compleja y multidimensional la explicación de integración regional; en la actualidad, con ciertas urgencias comunes como la de satisfacer las demandas sanitarias, político-económicas y sociales concretas surgidas o intensificadas a raíz de la pandemia y, a la vez, otras específicas de cada bloque en cuanto al logro y consolidación de sus objetivos económicos, y otros propios o singulares de cada experiencia de integración (denominados objetivos no económicos).

\section{Marco teórico de la integración regional}

Los autores clásicos que reflexionaron sobre que significa el término "integración regional" pusieron el acento en la integración como "proceso" con instituciones que poseen o exigen jurisdicción sobre los estados preexistentes (Haas, 1958), o un "proceso" en el cual dos o más actores forman un nuevo actor (Galtung, 1969); pero también integrar significa componer, constituir, formar, "hacer un todo o conjunto con partes diversas" (Deutsch, 1969). Cabe señalar, desde el punto de vista de la literatura económica moderna, a Jacob Viner (Zalduendo, 1998), quien en el año 1950 ya distinguió: 1) las áreas de libre comercio y las uniones aduaneras, 2) el mercado común y 3) la unión económica.

Sin embargo, en todos los casos la integración regional requiere de una acción constructiva, cuya dificultad está lógicamente relacionada con el número y la diversidad de partes a integrar. Es decir, requiere de la voluntad de los Estados de "crear" el proceso y la estructura o columna vertebral de la integración. Si dichas partes, o países, como ocurre en muchas experiencias de integración en curso, presentan notables diferencias internas, la integración se convierte en un delicado y lento proceso en el que los sentimientos nacionalistas y los reclamos procedentes de grupos o regiones se ven obligados a convivir con múltiples y variados argumentos económicos y políticos a favor y en contra de la integración (entre ellos, el euroescepticismo surgido en la UE y el antieuropeísmo que denostan el proceso de integración, generalmente encolumnados en partidos de extrema derecha). La tensión al interior de un Estado pone en vilo a toda la experiencia de integración regional.

Todo proceso de integración presenta algunas características que denotan la "identidad" de la integración, a saber:

1) Un marco geopolítico y una dimensión histórica al tiempo de construir los cimientos de la integración.

2) Una estructura orgánica o institucional en las cuales se reconocerán centros de deliberación y toma de decisiones del proceso. Si bien en la integración regional no se contempla la clásica división tripartita de poderes (en el sentido clásico de Montesquieu), si se asiste a distribución y asignación 
de roles ejecutivos, legislativos y judiciales adoptados y adaptados según el método de integración seguido por cada proceso o sea el método funcionalista (cuyo máximo exponente es el padre del europeísmo, Jean Monnet) o la cooperación intergubernamental.

3) Una dinámica propia de integración que se corresponde con los tiempos que demandará cada proceso. Se trata de las distintas fases y etapas para alcanzar las metas u objetivos de la integración. Producto de esta dinámica podríamos referir a la integración regional como un fenómeno inacabado en el cual se renuevan los desafíos a afrontar de acuerdo con el contexto de la integración y a los estados que forman parte de la experiencia.

4) La delegación de competencias de los Estados en las instituciones de la integración. Esta transferencia o cesión dependerá del tipo de integración: en el caso de la Unión Europea, conviven los gobiernos de los estados con un "gobierno común" de las instituciones supranacionales. En el caso de Mercosur, el método del consenso y la intergubernamentalidad en el seno de sus órganos ponen en evidencia una reticencia a operar dicha transferencia y una retención de competencias en manos de los Estados.

En un ámbito de interdependencia entre los Estados, se pueden diferenciar dos ámbitos de la integración regional: el externo y el interno; el primero, la integración subnacional y el segundo, a partir de la dimensión internacional y los problemas derivados del binomio multilateralismo-regionalismo.

\section{La integración subnacional: inclusión y exclusión}

Una de las tendencias predominantes es la formación de bloques regionales de Estados-Nación caracterizada por:

1) Plantear una cesión de soberanía, a la vez que el desmantelamiento de las fronteras (este desmantelamiento comporta una reducción o eliminación de barreras arancelarias y la paulatina supresión de las restricciones no arancelarias);

2) Contener un ingrediente importante de exclusión que se explica en función de la competitividad internacional. Con sentido crítico, se expresa que la tendencia globalizadora genera una internacionalización de los mercados, patrones de consumo, tecnologías, comunicaciones y producción, que generan una red internacional integrada, pero que excluye a la población vinculada a actividades tradicionales. Existe una separación entre el universo objetivado de los signos de la globalización y el conjunto de valores 
—expresiones culturales- que generan la multiplicación de agrupamientos comunitarios (Touraine, 1996).

Esta exclusión implica que no todas las áreas ni todas las regiones en el ámbito subnacional participan o están "comprendidas o incluidas" en el proceso de integración regional.

Existen una pluralidad de causas por las cuales esas regiones no son alcanzadas por el proceso de integración regional, pero el aporte, desde múltiples ámbitos (económico, social, territorial y jurídico), para superar la exclusión subnacional y favorecer la inclusión, es decir, la participación ya sea en la elaboración y toma de decisiones o bien en la aplicación de las políticas - en cada proceso- exige un replanteo de los objetivos, de la estructura institucional u orgánica y de los principios del esquema de integración. Una adecuada representación de intereses de las entidades subnacionales en la estructura de la integración parece ser la vía adecuada para permitir el diálogo, el intercambio de opiniones y la manifestación de intereses y necesidades, a la vez que se logra el compromiso de las regiones con los objetivos más amplios de la integración.

Es importante que el proceso de integración regional se dote de los instrumentos necesarios y apropiados para hacer posible la superación de desequilibrios regionales. Sin la puesta en marcha de una política que contemple a las regiones y países con desequilibrios de carácter territorial, de densidad poblacional, de desarrollo económico-social, el proceso de integración regional adolecerá de una endeblez intrínseca estructural.

\section{La dimensión internacional de la integración regional}

En este plano, se consideran elementos que distinguen lo que se ha denominado generalmente "relaciones externas" — en el caso de la UE- o "relacionamiento externo" - del Mercosur- o, en forma más general, "agenda externa". Con estas acepciones se hace referencia a una compleja red de acuerdos internacionales y relaciones tejidas, basada en las competencias cedidas por los estados al bloque para el manejo de las relaciones económicas internacionales como manifestación de la política comercial externa de la integración regional. La dimensión internacional está originariamente vinculada en todos los procesos al ámbito comercial y, específicamente, vinculada inexorablemente con el objetivo económico. La relación de los aspectos externos de objetivos no económicos asumidos por el bloque está aún restringida y dependerá más de la necesidad de fortalecimiento del papel interpretado por el bloque en el plano internacional que de las necesidades internas del propio proceso. 
De allí que esta dimensión conlleve:

1) Relaciones con los terceros estados, es decir, ajenos al proceso, suponiendo inclusive el envío o recepción de delegaciones con carácter permanente o transitorio (el denominado ejercicio del derecho de legación activa o legación pasiva).

2) Establecimiento de relaciones y conexiones con organizaciones internacionales (por ejemplo, la UE participa con carácter de observadora en la Asamblea General de la ONU).

3) Participación en varias negociaciones internacionales (por ejemplo, la UE intervino en las negociaciones en las ruedas del GATT y en la actualidad en el marco de la OMC o en las negociaciones sobre cambio climático).

4) Celebración de acuerdos internacionales, ya sea con terceros estados singularmente considerados o bien con otros esquemas de integración (el acuerdo UE-Mercosur(1)). En este punto, se debe reconocer que la elección de los actores, los acuerdos suscriptos y la vigencia de los mismos depende de necesidades del bloque, de decisiones tomadas en forma conjunta y de la letra de los Tratados constitutivos o fundacionales que son los que, en definitiva, otorgan la base legal para la negociación y celebración de acuerdos por el bloque, determinando la competencia de las instituciones u órganos en la materia.

Complementando lo anterior, el autor Sanahuja (2016) aprecia que las distintas opciones políticas e ideológicas de los Estados que han caracterizado el período comprendido entre 2005 y 2015 explican —en parte- las distintas formas que ha adoptado el regionalismo americano. Analizar cada una de estas iniciativas (los éxitos y fracasos en la materia) es una tarea muy extensa que excede los límites de este trabajo.

(1) En 1995, el Mercosur y sus Estados Partes y la Comunidad Europea y sus Estados miembros firmaron el Acuerdo Marco de Cooperación Interregional entre la Comunidad Europea y el Mercosur. Este Acuerdo es el precedente jurídico y el marco para las negociaciones que se sucedieron - con interrupciones- por más de veinte años hasta concluir el 28 de junio de 2019 con la firma del Acuerdo en principio entre la UE y el Mercosur. Los textos definitivos de este Acuerdo - a abril de 2021 - no han sido publicados y queda un largo camino por recorrer para su aprobación y entrada en vigencia. El 24 de agosto de 2019 se suscribió un Acuerdo con EFTA —o AELC Asociación Europea de Libre Comercio-. Los acuerdos con la UE y con EFTA son los más importantes negociados hasta el presente por el Mercosur dado el número de capítulos y materias abarcadas y el volumen de comercio involucrado. 


\section{Las reacciones de la integración regional ante la pandemia de COVID-19}

Un nuevo escenario se planteó a partir de la declaración realizada por la Organización Mundial de la Salud(2) (Seuba, 2011). En enero de 2020, la OMS declaró la emergencia de salud pública internacional - a raíz de COVID-19(3) — con el fin de prevenir y alertar a los Estados acerca de la necesidad de tomar medidas para prevenir su propagación (Velásquez, 2020).

Como precedentes en tiempos recientes de la grave crisis sanitaria, cabe mencionar que -en las décadas pasadas - se han declarado cinco emergencias (4) por parte de la OMS: el virus del H1N1, en 2009; la epidemia de casos de poliomielitis en 2014; la crisis del ébola en el oeste de África en 2014; la epidemia del virus del Zika en 2016 y el brote de ébola en la República Democrática del Congo que tuvo inicio en 2018 y fue declarado emergencia en 2019.

Desde marzo de 2020 se inició una etapa marcada por una serie de decisiones adoptadas por los Estados y la utilización de un léxico propio - y que se volvió sumamente frecuente- que incluye términos como cuarentena, emergencia sanitaria, contagios, cierre de fronteras y de aeropuertos y puertos nacionales e internacionales, autorizaciones, permisos, controles y el manejo y la difusión, cotidianamente, de cifras concernientes al número de contagiados, fallecidos y recuperados así como los porcentajes utilizados en forma comparativa para contar el número de hospitales, profesionales de la salud, terapias intensivas, respiradores, kits de diagnóstico y tratamiento de la enfermedad y nombres, origen y distribución de las vacunas, todos ellos asociados al COVID-19.

Muchas de las medidas de contención de la propagación del virus y de la diseminación del virus decantaron en medidas restrictivas e impactaron severamente en la economía, el comercio y el empleo dando lugar a una crisis económica particularmente severa y con disímil alcance según el grado de desarrollo del país y

(2) La Organización Mundial de la Salud fue creada en 1948 con el mandato de actuar como autoridad de dirección y coordinación de la labor sanitaria internacional. Trabaja con 194 Estados miembros, esparcidos en seis regiones.

(3) La OMS propuso el nombre provisional del coronavirus como "enfermedad respiratoria aguda 2019-nCoV" (n: nuevo; Cov: coronavirus). De acuerdo con la OMS, ese nombre cumple con las mejores prácticas para nombramiento de nuevas enfermedades infecciosas humanas, que se desarrollaron a través de un proceso de consulta entre agencias asociadas. El nombre final de la enfermedad (COVID-19) fue proporcionado por la Clasificación Internacional de Enfermedades a través del Comité Internacional de Taxonomía de Virus.

(4) Según la OMS, una Emergencia de Salud Pública de Preocupación Internacional es "un evento extraordinario que se determina que constituye un riesgo para la salud pública de otros Estados a través de la propagación internacional de la enfermedad y que potencialmente requiere una respuesta internacional". 
de la región. Asimismo, la información acerca de la enfermedad también adquirió en los medios de difusión y por parte de los comunicadores familiaridad con el vocabulario y cotidianeidad en el uso. Sin embargo, también surgieron, a raíz de la pandemia, las denominadas "infodemia" y las "fake news" (Larsen, 2020), es decir, el fenómeno de comunicación que la propia OMS refirió con el término "infodemia": o sea una crisis en la información que conlleva a la divulgación de noticias falsas o que persiguen desinformar provocando escepticismo, falta de confianza y de seguridad en el público (Burrull, 2020).

En síntesis, la pandemia de COVID-19 desencadenó tres distintos tipos de crisis: la crisis sanitaria, la crisis económica y la crisis en la información, relacionadas entre sí, pero con singularidades y alcances diferenciados. Además, no se debe olvidar que ellas se enmarcan en un panorama caracterizado por los tres escenarios descritos en el primer punto de este trabajo.

En este escenario de múltiples crisis, sumamente complejo, los actores han sido - inicialmente- los Estados y las organizaciones internacionales (principalmente la ONU, la OMS y los organismos regionales especializados en materia de salud, como la Organización Panamericana de la Salud, por ejemplo). Sin embargo, ha alcanzado a la integración regional. Sin dudas, la integración regional se encontró con este nuevo desafío tratando de dar respuestas o complementar las acciones estatales que se demostraron insuficientes o inadecuadas, elaborando estrategias conjuntas, diseñadas e implementadas desde el ámbito regional.

Ciertamente la experiencia europea - muy vasta en el tiempo y acostumbrada a transitar muchos caminos no exentos de tropiezos y dificultades- es la que más denota la cristalización de acciones que culminan en una política para enfrentar a la crisis sanitaria, económica y de la información, desatada a raíz de la pandemia. Otros bloques, como el Mercosur, han intentado - con relativo éxito- explorar iniciativas conjuntas y algunas acciones concretas.

\section{V.1. La Unión Europea}

La Unión Europea respondió al desafío de la pandemia, superando el desconcierto y la sorpresa iniciales. Inicialmente, Ursula Von der Leyen, máxima autoridad de la Comisión, y el presidente del Consejo Europeo presentaron una hoja de ruta. En este punto, para responder ante la contingencia sanitaria, se adoptaron medidas de carácter nacional y estrategias a nivel de la UE. La Comisión Europea presentó su plan para salir de la recesión de 2020, con un fondo de reconstrucción (5) de 750.000 millones de euros, el cual fue aprobado por los 27 mandatarios

(5) Para mayor información, ver https://ec.europa.eu/info/strategy/recovery-plan-europe_es 
europeos. Según la Comisión Europea, el PIB de las 19 economías del euro en su conjunto se contraería un $7,7 \%$ en el año 2020 a raíz de la crisis sanitaria. Otra iniciativa denominada Global Response, impulsada por la UE para enfrentar la pandemia, propuso, a partir de la obtención de financiamiento, el desarrollo de una vacuna y el tratamiento contra el nuevo coronavirus.

Posteriormente, ya en diciembre de 2020, el presidente del Consejo Europeo, Charles Michel, dio a conocer las cuatro prioridades en materia de crisis económica a raíz de la pandemia: el funcionamiento del mercado interior, una estrategia de inversión masiva, las acciones exteriores de la UE(6) y la resiliencia y gobernanza de la UE. Puntualmente, la estrategia de recuperación se centra, de acuerdo con la propuesta del Eurogrupo, en crear redes de seguridad para trabajadores, empresas y los Estados miembros de la UE. Asimismo, se anunció la puesta en marcha de un fondo de recuperación destinado a los Estados más afectados. A su vez, la UE ha fijado cuatro prioridades: limitar la propagación del virus, garantizar el suministro de equipos médicos, promover la investigación y vacunas y apoyar el empleo, las empresas y la economía.

En la reunión del Consejo Europeo (celebrada los días 10 y 11 de diciembre de 2020) han sido adoptadas decisiones muy importantes en torno a los ejes temáticos que se sintetizan en el documento EUCO 22/20 (7).

1) En primer lugar, el desarrollo de vacunas (Ramirez, 2021) eficaces contra la COVID-19 y la conformidad ante la celebración de acuerdos de adquisición anticipada por la Comisión.

Los contratos firmados por la Comisión constituyen una cartera diversificada de vacunas para Europa y hasta el 17 de diciembre de 2020 fueron suscriptos con AstraZeneca, Sanofi-GSK, Janssen Pharmaceutica NV, BioNtech-Pfizer, CureVac, Moderna y Novavax.

Los contratos forman parte de la estrategia europea (que fuera establecida en junio de 2020) para acelerar el desarrollo, la fabricación y el despliegue de vacunas eficaces y seguras contra COVID-19. A cambio del derecho a comprar un número determinado de dosis de vacunas en un período concreto, la Comisión financió parte de los costes iniciales de los productores de vacunas a través de compromisos anticipados de mercado. La

(6) Al respecto puede consultarse el comunicado de prensa de la Comisión Europea denominado Coronavirus: EU global response to fight the pandemic, Bruselas, 8 de abril de 2020.

(7) El documento EUCO 22/20 se complementa con declaraciones posteriores. Es de especial relevancia la Declaración de los miembros del Consejo Europeo sobre la COVID-19 y la sanidad, de fecha 25 de febrero de 2021. 
financiación aportada se considera un pago a cuenta de las vacunas que los Estados miembros compren realmente.

Para ingresar al mercado, las vacunas deben ser aprobadas por la Agencia Europea de Medicamentos (EMA) en cuanto a calidad, seguridad y eficacia. En tal sentido, la Comisión adoptó una serie de medidas clave (en octubre de 2020) para que los Estados miembros desarrollen estrategias nacionales de vacunación. La EMA es la única autorizada para otorgar la autorización de uso condicional de comercialización de la vacuna. Asimismo, esta agencia es responsable del Comité de Farmacovigilancia y del desarrollo y mantenimiento de EudraVigilance, un sistema de gestión y análisis de la información sobre las presuntas reacciones adversas a los medicamentos autorizados en el Espacio Económico Europeo.

2) En segundo término, se subraya la importancia de los preparativos para el despliegue y la distribución oportunos de las vacunas, destinadas a garantizar que los habitantes de la UE puedan disponer de vacunas en cuanto sea posible y de manera coordinada.

3) La importancia de proporcionar información objetiva y clara sobre las vacunas y luchar contra la desinformación.

4) A su vez, se insiste que la vacunación debe tratarse como un bien público mundial.

5) La UE continuará sus esfuerzos por contribuir a la respuesta internacional a la pandemia, en particular a través del Mecanismo COVAX, destinado a garantizar un acceso asequible y equitativo a las vacunas en particular, en 92 países de renta baja y media.

6) Por su parte, el Consejo Europeo invitó a la Comisión a que presente una propuesta de Recomendación del Consejo relativa a un marco común para las pruebas rápidas de antígenos y para el reconocimiento mutuo de los resultados de las pruebas.

7) El Consejo Europeo destaca la necesidad de impulsar los trabajos sobre las propuestas relativas a la Unión de la Salud y la Estrategia Farmacéutica, en particular las relativas al acceso a los medicamentos en todos los Estados miembros, aprovechando los datos sanitarios en Europa y la coordinación entre las estrategias nacionales y la estrategia de la UE.

8) Promover la cooperación internacional y, en particular, un tratado internacional sobre pandemias, en el marco de la Organización Mundial de la 
Salud. Además de colaborar con la revisión del Reglamento Sanitario Internacional (en siglas RSI).

9) En cuanto a los efectos de la pandemia sobre la movilidad de personas, se asume que la pandemia es aún una realidad. Dado que la situación epidemiológica en Europa sigue siendo preocupante, se ratifica la coordinación de los esfuerzos a nivel de la UE, en particular para preparar el levantamiento progresivo de las restricciones y el regreso a condiciones de viaje normales, también para el turismo transfronterizo ni bien mejoren las condiciones sanitarias.

A propósito de la iniciativa de un tratado internacional sobre la prevención y preparación ante pandemias, fue hecha pública en el Foro de París de la Paz, en noviembre de 2020. Posteriormente, el 30 de marzo de 2021, el presidente del Consejo Europeo y el director general de la Organización Mundial de la Salud, Tedros Adhanom Ghebreyesus, realizaron la convocatoria a favor de un tratado internacional sobre pandemias. Nótese el protagonismo asumido por la UE con esta iniciativa, asumiendo el liderazgo sanitario en la convocatoria para la suscripción de un tratado en la materia.

Desde el punto de vista jurídico, el mencionado tratado podría adoptar la forma de un convenio marco en virtud de la Constitución de la OMS, que en su artículo 19 atribuye a la Asamblea Mundial de la Salud "autoridad para adoptar convenciones o acuerdos respecto a todo asunto que esté dentro de la competencia de la Organización" (8).

Una vez que la Asamblea adoptara el tratado en el ámbito internacional (todos los estados miembros de la OMS se reúnen en la Asamblea), luego se abriría una instancia de ratificación o aprobación a nivel nacional, debiéndose alcanzar el número de ratificaciones necesarias para su entrada en vigor. El instrumento sería jurídicamente vinculante para los países que lo ratificaran.

El objetivo de este tratado sería constituir "el" instrumento de referencia en la lucha contra futuras pandemias sustentado en principios de cooperación internacional y transparencia.

(8) Este artículo se utilizó, por ejemplo, en 2003, para la adopción del Convenio Marco para el Control del Tabaco. 
En concreto, la iniciativa se focalizaría en:

- La detección y prevención precoces de pandemias.

- La resiliencia frente a futuras pandemias.

- La respuesta a futuras pandemias, en particular garantizando el acceso universal y equitativo a soluciones médicas como vacunas, medicamentos y diagnósticos.

- Un marco sanitario internacional más sólido, con la OMS como autoridad coordinadora de las cuestiones sanitarias a escala mundial.

- El concepto de "una sola salud", que conecte la salud de las personas, de los animales y del planeta.

Por otra parte, resulta interesante observar la evolución en la base jurídica de la acción de la UE en materia de salud, con base en la cual se articula toda la normativa adoptada por las instituciones y las acciones desarrolladas. En primer lugar, es menester aclarar que los estados miembros de la Unión son los primeros responsables de la protección de la salud y de los servicios de salud. En los tratados de Roma no se contemplaba ninguna disposición, tampoco en Acta Única Europea, pero con el Tratado de la Unión Europea, vigente desde 1993, se introdujo la salud pública y con el Tratado de Ámsterdam, vigente a partir de 1999, se aclaró el tema de competencias: las competencias originarias corresponden a los estados miembros y la UE podrá adoptar medidas para garantizar un nivel alto de protección de salud y, a la vez, también cooperar en relación con toda amenaza que entrañe peligro.

En esta línea, los artículos 9 y 168 apartado 1 del TFUE —en vigor desde 2009y la Carta de Derechos Fundamentales de la UE garantizan que, al definirse y ejecutarse las políticas y acciones de la Unión, se observe un alto grado de protección de la salud humana.

Es esta una premisa denominada "STP", que guía el accionar de la Unión y que de forma transversal (enfoque horizontal e interdisciplinario) permite su observancia en el marco de toda otra política. La UE ha implementado la estrategia "Salud para el Crecimiento", junto con el tercer programa aprobado (para el periodo 2014-2020) y, a su vez, también es referencia obligada para el cuarto programa para el período 2021-2027 denominado "UE proSalud". Cabe destacar que los programas plurianuales se adoptan desde 1993 y que a la luz del tercer programa se creó una de las agencias a la que se referirá posteriormente.

Los objetivos de la estrategia son: 1) promover la buena salud; 2) proteger a los ciudadanos frente a amenazas para la salud, es decir, mejorar los sistemas de 
vigilancia (por ejemplo, prevención de enfermedades, pandemias y bioterrorismo);3) apoyar a sistemas sanitarios dinámicos.

La observancia de estos objetivos permite velar por el desarrollo de la consecución de las libertades de circulación de bienes y personales, ofreciendo garantías para la salud pública; en otros términos, tiende a la consolidación del mercado interior o espacio sin fronteras.

Además de las instituciones de la UE (Consejo, Comisión y Parlamento) se ocupan del seguimiento e implementación de la regulación agencias especializadas, a saber:

1) La Agencia Europea de Medicamentos -EMA—.

2) Centro Europeo para la Prevención y el Control de las Enfermedades -ECDC-.

3) Agencia Europea de Sustancias y Mezclas Químicas —ECHA—.

4) Agencia Europea de Seguridad alimentaria -EFSA-.

5) Agencia Ejecutiva de Sanidad y Consumo - EACH-.

Cabe agregar que, en el marco de la pandemia de COVID-19, se ha pensado en reforzar con una sexta agencia (prevista para octubre de 2021) que se denominará Autoridad Europea de Preparación y Respuesta ante Emergencias Sanitarias (HERA).

\section{V.2. El Mercosur}

En cuanto al Mercosur, en marzo de 2020 los presidentes de la región acordaron medidas para combatir el Covid-19 en cuanto a cuatro ejes (Negro, 2021): compras públicas, fomento de comercio, control de fronteras y recuperación de la economía; entre ellas, la necesaria coordinación de medidas sanitarias a nivel regional.

Asimismo, como parte de las acciones se analizó la posibilidad de realizar compras de medicamentos e insumos hospitalarios y médicos en forma conjunta; luego se examinó el fomento del comercio y de la economía y la necesidad de los controles fronterizos de personas para evitar la propagación del coronavirus en la región y, a la vez, libre circulación de elementos médicos e insumos hospitalario. También fue creado un Fondo de Emergencia con recursos financiados a través del Fondo de Convergencia Estructural del Mercosur (FOCEM), destinado al combate coordinado de la Pandemia y a reducir las asimetrías sanitarias entre 
los Estados Partes, para la producción de 50.000 pruebas moleculares rápidas, conocidas como kits PCR para el diagnóstico del coronavirus y 400.000 tests que detectan la enfermedad en el suero de los pacientes. Se acordó que los kits fueran producidos por el Instituto Pasteur de Uruguay y elaborados con el aporte de los científicos de la Universidad de la República, además de otros organismos.

En otro orden, cabe destacar la utilización de video conferencia - por primera vez en su historia - en la Cumbre de presidentes del Mercosur, así como la reunión ordinaria del Consejo del Mercado Común (CMC); ambas se celebraron entre el 29 de junio y el 2 de julio de 2020 debido a la pandemia de la Covid-19 en la región. En la reunión se trataron, entre otros temas: la articulación de políticas conjuntas para "hacer frente a los retos económicos y sociales derivados" de la pandemia, la situación del proceso de integración regional, y el trabajo de relacionamiento externo desarrollado durante la presidencia pro tempore de Paraguay.

En lo concerniente a la salud pública en el ámbito Mercosur, si bien el tratado de Asunción no contemplaba la salud pública entre sus objetivos, conforme el proceso evolucionó se crearon dos instancias de trabajo el Subgrupo de Trabajo No 11 - SALUD (SGT No 11) y las Reuniones de Ministros de Salud (RMS).

Ambos órganos se expresan a través de documentos de trabajo que son elevados a dos de los Órganos con capacidad decisoria en el Mercosur, o sea el Consejo Mercado Común -CMC—y el Grupo Mercado Común —GMC—.

El Subgrupo de Trabajo No 11 depende del Grupo del Mercado Común y es un órgano técnico en el que se abordan las cuestiones referidas a la armonización de las legislaciones nacionales en materia de regulación de la salud, así como de los sistemas de control sanitario entre los Estados parte. Con base en el reconocimiento mutuo de productos sanitarios se persigue que el producto pueda circular sin la necesaria autorización de cada autoridad sanitaria a nivel nacional.

A la vez, sus trabajos se orientan en el sentido de reducir los riesgos para la salud a partir de la articulación de los sistemas nacionales para la calidad, eficacia y seguridad de los productos y servicios en circulación en el espacio mercosureño.

Asimismo, se trabaja en la promoción del libre ejercicio de profesionales y técnicos de la Salud en los Estados parte. Está compuesto por representantes de cada uno de los Estados parte, que deliberan acerca de la armonización de disposiciones nacionales y propuestas de resoluciones que son elevadas al GMC. Tienen diálogo con el sector privado y este puede participar con carácter de observador en diversas etapas, por ejemplo, en la Comisión de Productos para la Salud. 
En cuanto a la Reunión de ministros de Salud del Mercosur, la misma fue creada por el Consejo del Mercado Común en 1995 con el objetivo general de avanzar hacia la coordinación de políticas en el ámbito de la Salud para el Mercosur. Su principal objetivo es el análisis de las políticas regionales en salud, y debatir y en lo posible elaborar acciones conjuntas en torno a temas comunes definidos por los ministros del Área. Carecen de la posibilidad de adoptar propuestas normativas con carácter vinculante; su función es de carácter técnico. El organigrama de salud se completa con diversas comisiones intergubernamentales a las cuales se les atribuyen competencias específicas para debatir en torno a temas específico y explorar vías de cooperación internacional, y de ser el caso, convenir propuestas de disposiciones y/o acuerdos para la suscripción de ministros.

\section{Reflexiones finales}

Los escenarios descriptos en la etapa anterior a la pandemia presentaban un conjunto de desafíos a los cuales se podía dar respuesta de diversa forma. La integración económica regional surgió en sus diversas facetas y exploró alternativas para la consecución de sus múltiples objetivos, pero primordialmente para alcanzar el objetivo económico que distingue a cada experiencia.

No obstante, 2020 será recordado como un año en el cual se hicieron evidentes insuficiencias y carencias. Este año puso en evidencia el surgimiento de una crisis sanitaria, a la vez que económica y de la información.

En tal sentido, puede concluirse que la estructura institucional de la UE y la complejidad del respectivo entramado jurídico, si bien se han visto sorprendidos por la pandemia, pasado el primer momento han elaborado una serie de respuestas y dado vida a una estrategia de prevención y respuesta COVID-19 que podría desembocar en una verdadera política sanitaria.

Es importante comprender que la estrategia europea desplegada hasta el presente es "transversal", es decir, no se restringe al ámbito sanitario, sino que alcanza a las regulaciones económicas, supone esfuerzos y gestión conjunta de los recursos financieros, y acuerda aspectos políticos para la distribución de vacunas y más aún otorga un rol preponderante a nivel sanitario internacional apoyado en tres dinámicas: la participación en el mecanismo COVAX, la propuesta de un tratado internacional de pandemias, y la iniciativa de la vacuna como bien público mundial.

La propuesta de este Tratado internacional de pandemias es un primer paso en la afirmación de un liderazgo en materia sanitaria por la UE. Será menester seguir con atención los pasos sucesivos, a la vez que resultará interesante observar el desarrollo de la Cumbre Mundial de la Salud del G-20, a realizarse en Roma, el 21 
de mayo de 2021, escenario que permitirá a la UE ratificar su compromiso con la cooperación multilateral para enfrentar las amenazas sanitarias actuales y futuras y trabajar en el concepto de seguridad sanitaria.

En orden al Mercosur, de acuerdo con su método de adopción de decisiones y la conformación de los órganos, como ha sido señalado, sus competencias en lo atinente a la salud pública no estaban contempladas en el tratado de Asunción, aunque sucesivamente fueron incorporadas a través de la previsión en el funcionamiento de órganos con competencias técnicas, como el Subgrupo de trabajo № 11 y un segundo órgano - eminentemente político- como la Reunión de Ministros de Salud.

La pandemia de COVID-19 puso en evidencia que las estructuras de los Estados Nacionales no son suficientes para satisfacer los requerimientos a los cuales los enfrenta la pandemia.

Allí donde la acción del Estado no basta, se hace necesario definir estrategias y coordinar esfuerzos para implementar acciones eficaces a nivel regional. La adopción de políticas regionales en materia de salud públicas parece revelarse como una necesidad imperiosa. La integración puede ser una o la única alternativa viable ante la insuficiencia de los sistemas sanitarios nacionales.

\section{Bibliografía}

Berlin, I. (1983). Contra la corriente. México: Fondo de Cultura Económica.

Burrull, A. L. (2020). Fake news e infodemia científica durante la Covid-19, ¿dos caras de la misma crisis informacional? Anuario ThinkEPI. España.

Carbone, F. (2020). Trade News. Recuperado de https://tradenews.com.ar/ rcep-multilateralismo-regionalismo-y-el-afianzamiento-del-liderazgo-chino/ [Fecha de consulta: 28/11/2021].

Fofack, H. (2018). La competitividad económica de África. Recuperado de https://www.imf.org/external/pubs/ft/fandd/spa/2018/12/pdf/fofack.pdf [Fecha de consulta: 06/04/2021].

SWI swissinfo.ch. (2021). La cumbre de Roma, una oportunidad de "prevenir crisis sanitarias mundiales". Recuperado de https://www.swissinfo.ch/spa/g20salud_la-cumbre-de-roma--una-oportunidad-de--prevenir-crisis-sanitariasmundiales-/46512162 
Huntington, S. (1997). El choque de civilizaciones y la reconfiguración del orden mundial. Barcelona: Paidós.

Keohane, R. (2012). Power and Interdependence. Nueva York: Longman Classics in Political Science.

Larsen, F. (2020). Coronavirus, fake news e infodemia. Recuperado de https:// www.iri.edu.ar/index.php/2020/04/23/coronavirus-fake-news-e-infodemia/

Messner, D. (1999). La transformación del Estado y la Política en el proceso de globalización. Nueva Sociedad (pp. 71-91). Buenos Aires: Fundación Friedrich-Ebert.

Negro, S. (2021). Quo Vadis?, Na 2. Recuperado de http://www.derecho.uba.ar/ institucional/observatorio-acuerdo-mercosur-ue/publicaciones.php

Ramirez, B. (2021). LACES. Recuperado de https://eurolatinstudies.com/ laces/announcement/view/27

Sanahuja, J. (2016). Regionalismo e integración en América Latina: De la fractura del Atlántico -Pacífico a los retos de una globalización en crisis. Pensamiento propio, No 44. Recuperado de http://www.cries.org/wp-content/ uploads/2017/02/007-sanahuja.pdf

Touraine, A. (1996). ¿Podremos vivir juntos? El destino del hombre en la aldea global. México: Fondo de Cultura Económica.

Velásquez, G. (noviembre de 2020). Las reformas de la Organización Mundial de la Salud en la época de Covid-19, Documento de investigación 121 (S. Centre, Ed.). Recuperado de https://www.southcentre.int/wp-content/uploads/2020/11/ RP-121_ES.pdf

Seuba, X. y Negro, S. (coord.) (2011). Pasado y presente de las Organizaciones Internacionales OACI, OMPI, OMS y OEA, $1^{\text {a }}$ ed. Buenos Aires: La Ley.

Zalduendo, E. (1998). Breve Historia del Pensamiento Económico, $3^{\mathrm{a}}$ ed. Buenos Aires: Ediciones Macchi.

Fecha de recepción: 30-04-2021

Fecha de aceptación: 10-08-2021 